\title{
Quantifying the influence of ground motion duration on structural collapse capacity using spectrally equivalent records
}

\author{
Reagan Chandramohan, ${ }^{\text {a) }}$ M.EERI, Jack W. Baker, ${ }^{\text {a) }}$ M.EERI, and Gregory G. \\ Deierlein, ${ }^{\text {a) }}$ M.EERI
}

This study examines the influence of ground motion duration on the collapse capacities of a modern, five-story steel moment frame and a reinforced concrete bridge pier. The effect of duration is isolated from the effects of ground motion amplitude and response spectral shape by assembling sets of "spectrally equivalent", long and short duration records, and employing them in comparative non-linear dynamic analyses. For the modern steel moment frame, the estimated median collapse capacity is $29 \%$ lower when using the long duration set, as compared to the short duration set. For the concrete bridge pier, the collapse capacity is $17 \%$ lower. A comparison of commonly used duration metrics indicates that significant duration is the most suitable metric to characterize ground motion duration for structural analysis. Sensitivity analyses to structural model parameters indicate that structures with high deformation capacities and rapid rates of cyclic deterioration are the most sensitive to duration.

\section{INTRODUCTION}

The influence of ground motion duration on structural demands is a topic that has been researched extensively in the literature. As summarized in Hancock and Bommer (2006), previous studies have drawn different conclusions depending on the structural demand parameters they considered. The few that considered only peak structural deformations (e.g. Sarieddine and Lin 2013) generally found duration to have little effect. Most others studies (e.g. Bommer et al. 2004, Cornell 1997, Hancock and Bommer 2007, Iervolino et al. 2006, Oyarzo-Vera and Chouw 2008, and Raghunandan and Liel 2013) found that although duration does not influence peak deformations, it does influence cumulative damage indices.

\footnotetext{
a) Dept. of Civil and Environmental Engineering, Stanford University, Stanford, CA 94305, USA
} 
Current seismic design standards and loading protocols for component testing do not explicitly account for the effects of duration. ASCE (2010) attempts to do so, implicitly, by specifying that accelerograms to be used for structural analysis should be chosen from earthquakes having magnitudes consistent with those that control the risk-targeted maximum considered earthquake (MCER) (ASCE 2010) ground motion. Even alternative performancebased evaluation methodologies (e.g. FEMA 2012 and PEER 2010a) do not have a welldefined framework for incorporating the effects of ground motion duration, apart from qualitative ground motion selection.

This study aims to highlight the importance of considering duration when selecting ground motions for structural response analysis, with particular emphasis on evaluating structural collapse. Structural collapse capacity is an important metric used to calibrate seismic design codes, whose main aim is to ensure safety against collapse (ASCE 2010). Collapse is also an important limit state in performance-based loss evaluation (Moehle and Deierlein 2004). Evaluating the influence of ground motion duration on collapse capacity requires numerical models that accurately characterize structural behavior at large non-linear deformations. Ideally, such models should incorporate the in-cycle and cyclic deterioration of strength and stiffness of structural components (Ibarra et al. 2005), as well as the destabilizing $P-\Delta$ effects of gravity loads (Gupta and Krawinkler 2000). Many prior studies (e.g. Hancock and Bommer 2007, Iervolino et al. 2006, Oyarzo-Vera and Chouw 2008, and Sarieddine and Lin 2013) employed numerical models that did not incorporate all these features, and hence, may not provide a comprehensive assessment of the influence of duration on collapse safety. By incorporating deterioration and $P-\Delta$ effects, this study provides an informative assessment of the effect of duration, including analyses to evaluate the sensitivity of the observed effect of duration to model parameters.

A number of other studies (e.g. Chai and Fajfar 2000, Krawinkler 1997, Kunnath and Chai 2004, Malhotra 2002, Sucuoglu and Nurtug 1995, and Zahrah and Hall 1984) have identified total dissipated hysteretic energy as an indicator of structural damage, and considered ground motion duration to act as a proxy for this demand measure. They have also attempted to quantify the damage potential of accelerograms based on the hysteretic energy dissipated by single-degree-of-freedom oscillators. In this study, structural damage is not explicitly quantified in terms of the dissipated hysteretic energy, but the cumulative hysteretic energy dissipated by each plastic hinge is used to cyclically degrade its strength 
and stiffness after each inelastic excursion, such that damage is manifested in the form of larger structural deformations under intense, long duration ground motions, eventually leading to structural collapse.

In addition to the issues associated with the reliable modeling of deterioration, three challenges that have hampered studies on the influence of ground motion duration on structural response are (1) the scarcity of long duration ground motions, (2) the difficulty in isolating the effects of duration from other ground motion characteristics, such as amplitude and frequency content, and (3) the lack of consensus on an effective ground motion duration metric that relates to structural behavior. The first challenge has been addressed in some previous studies (e.g. Mahin 1980, Raghunandan and Liel 2013, Rahnama and Manuel 1996, Sarieddine and Lin 2013, Tremblay 1998, and Xie and Zhang 1988) through the use of artificially simulated, long duration accelerograms. In this study, the scarcity of available ground motions has been addressed by collecting and utilizing long duration ground motions recorded from recent large magnitude earthquakes, most notably the 2008 Wenchuan (China), 2010 Maule (Chile), and 2011 Tohoku (Japan) earthquakes. The second challenge of isolating the effect of duration from other ground motion characteristics has been previously addressed by Hancock and Bommer (2007), Montejo and Kowalsky (2008), and Ou et al. (2014) by modifying the spectral content of recorded accelerograms to have similar response spectra. Sideras and Kramer (2012) used stochastically simulated accelerograms having similar amplitude and frequency characteristics, but different durations. This study employs spectrally equivalent, long and short duration record sets, with unmodified spectral content, to isolate and quantify the influence of duration. The third challenge is addressed by analyzing several ground motion duration metrics to identify which one is best suited for selecting ground motions to use in non-linear collapse analyses.

\section{GROUND MOTION SELECTION AND COLLAPSE CAPACITY ESTIMATION}

The collapse capacity of a structure can be treated as a random variable, defined as the intensity of ground excitation that causes structural collapse. Its cumulative distribution function, known as a collapse fragility curve, relates ground motion intensity to the probability of collapse. Calculation of collapse capacity requires a non-linear structural model that can accurately simulate response from the initiation of inelasticity up to the onset of collapse at large deformations. The non-linear response is evaluated by scaling ground motions to different intensity levels, the distributions of whose characteristics (such as 
frequency content, duration, and pulse-like characteristics) at each intensity level, match their respective predicted distributions corresponding to the site-specific seismic hazard. When a different set of ground motions is used at each intensity level, the procedure is referred to as multiple stripe analysis (Jalayer 2003). This is in contrast to incremental dynamic analysis (IDA), whereby a single set of ground motions is scaled to different intensity levels (Vamvatsikos and Cornell 2002). Multiple stripe analysis is generally preferred for buildingspecific applications since it captures site-specific hazard conditions. In this study, however, $I D A$ is employed for the purposes of comparative collapse analyses using two sets of spectrally equivalent ground motions with different durations. Ground motion intensity is defined by the $5 \%$ damped pseudo spectral acceleration at the fundamental period of the structure, $S_{a}\left(T_{1}, 5 \%\right)$.

The frequency content of a ground motion is commonly characterized by its response spectral shape, whose influence on predicted collapse capacity has been demonstrated in previous studies (e.g. Baker and Cornell 2006 and Haselton et al. 2011). This study evaluates whether ground motion duration influences structural collapse capacity as well, thereby warranting consideration during record selection for collapse analysis, in addition to response spectral shape. Bradley (2010) proposes a framework to determine the predicted distribution of duration at a site, conditional on a chosen intensity level. This conditional distribution of duration can be obtained using seismic hazard deaggregation information, a ground motion prediction equation for duration (e.g. Abrahamson and Silva 1996, Bommer et al. 2009, and Kempton and Stewart 2006), and information on the correlation between the residuals (epsilon values per Baker and Cornell 2005) of duration and response spectral ordinates (e.g. Bradley 2011).

The selected ground motions are used as input to non-linear dynamic structural analyses, where the collapse limit state is defined by the unbounded increase in peak global deformations, above a pre-defined threshold (Haselton and Deierlein 2007). The probability of collapse at each intensity level is computed as the fraction of ground motions causing collapse at that intensity level. The collapse fragility curve is then determined by fitting a lognormal cumulative distribution function to these data points using a maximum likelihood approach. 


\section{CREATION OF RECORD SETS}

A major component of this study entailed assembling a set of long duration ground motions from earthquake recordings. Significant duration $\left(D s_{5-75}\right)$ was used to characterize ground motion duration since it has been widely used in the literature, and preliminary studies by the authors (Foschaar et al. 2011) indicated it to be the preferred metric for this kind of analysis. The significant duration of a ground motion is defined as the time interval over which a specific percentage of the following integral is accumulated,

$$
\int_{0}^{t_{\max }} a(t)^{2} d t
$$

where $a(t)$ represents the ground acceleration and $t_{\text {max }}$ represents the length of the record. As shown in Figure 1, the 5-75\% qualifier on significant duration refers to the percentages of the integral defined in Equation 1, over which the significant duration is defined. It is later demonstrated that the choice of $D s_{5-75}$ for selecting records does not significantly influence the final results, though significant duration is shown to be a more robust and convenient predictor of the effect of duration on structural collapse than other metrics.

To assemble the long duration record set, approximately 2000 horizontal record pairs were collected from the following large magnitude earthquakes: 1974 Lima (Peru), 1985 Valparaiso (Chile), 1985 Michoacan (Mexico), 2003 Hokkaido (Japan), 2010 Maule (Chile), and 2011 Tohoku (Japan). They were baseline corrected and filtered using the

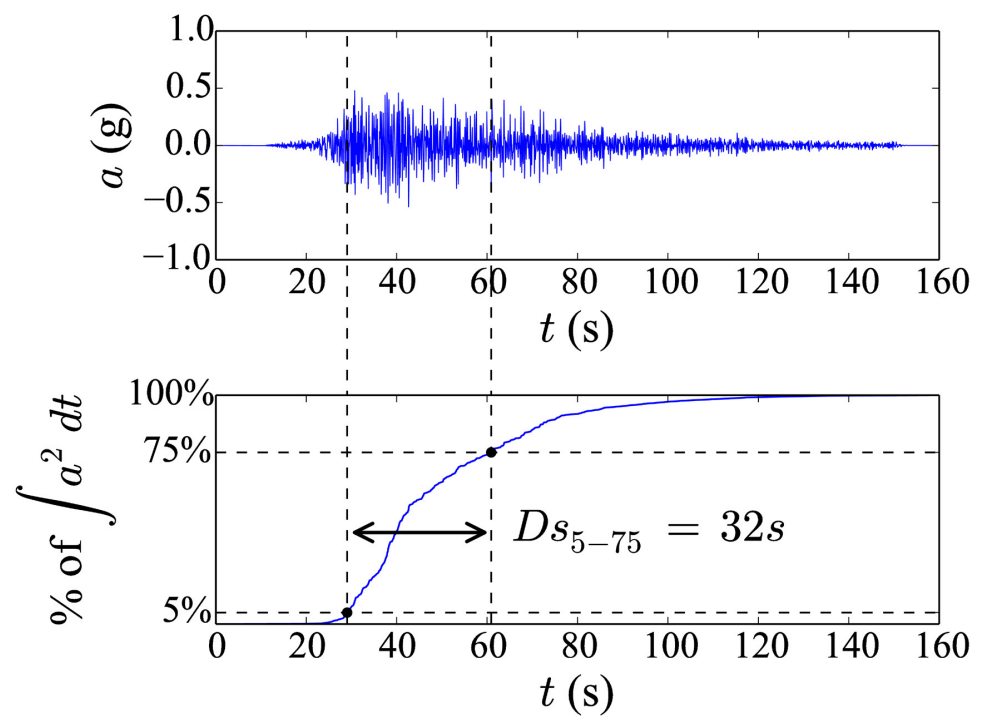

Figure 1. Computation of the 5-75\% significant duration $\left(D s_{5-75}\right)$ of a ground motion. 
recommendations of Boore and Bommer (2005) and Boore (2005). Record pairs from the following large magnitude events in the PEER NGA-West2 database (Ancheta et al. 2013) were also included in the collection: 1992 Landers (USA), 1999 Kocaeli (Turkey), 2008 Wenchuan (China), and 2010 El Mayor Cucapah (USA). Since the selected ground motions were to be used for collapse analyses requiring fairly high intensities, record pairs with geometric mean peak ground acceleration $(P G A)$ smaller than $0.1 \mathrm{~g}$ or geometric mean peak ground velocity $(P G V)$ smaller than $10 \mathrm{~cm} / \mathrm{s}$ were screened out. From the resulting database, long duration record pairs were identified as those with $D s_{5-75}$ of at least one of the two components greater than $25 \mathrm{~s}$. The $25 \mathrm{~s}$ threshold was decided after reviewing a histogram of $D s_{5-75}$ of all available records, striking a balance between being long enough to observe an effect of duration, but not so long as to result in too small of a set. The threshold was applied to the $D s_{5-75}$ of individual components rather than the geometric mean $D s_{5-75}$ of both components since doing so would have screened out some viable long duration records. Long duration records from soft soil sites were also screened out since it was felt that soft soil records have unique characteristics that would require selection criteria beyond response spectral shape to maintain parity between long and short duration record pairs. Finally, to avoid having any single event dominate the record set, the number of record pairs selected from any event was limited to 25. This process resulted in the creation of a long duration record set containing 73 record pairs, with a geometric mean $D s_{5-75}$ of $42 \mathrm{~s}$. As a point of reference, $42 s$ corresponds to the predicted median $D s_{5-75}$ for a magnitude 9.1 earthquake, at a source distance of $100 \mathrm{~km}$, using Abrahamson and Silva (1996). The distribution of $D s_{5-75}$ for this long duration set is shown in the upper portion of Figure 2. As summarized in Table 1, ground motions are included from 10 earthquakes, and records from the 2011 Tohoku and 2008 Wenchuan earthquakes constitute over half of the set.

A companion short duration record set was assembled to serve as a control group. For each of the 146 individual records in the long duration set, a corresponding record with $D s_{5-75}$ smaller than $25 s$ and having a closely matching response spectrum was chosen from the PEER NGA-West2 database. To find a short duration record with a response spectrum closely matching that of a given long duration record, the target response spectrum of the long duration record was discretized at periods from $0.05 s$ to $6.00 s$, at intervals of $0.05 s$, to obtain 120 spectral ordinates, $L_{1}, L_{2}, L_{3}, \ldots, L_{120}$, with mean $\bar{L}$. The corresponding response spectral ordinates, $S_{1}, S_{2}, S_{3}, \ldots, S_{120}$ with mean $\bar{S}$, were calculated for all records 
Table 1. Summary of the number of record pairs from each earthquake in the long duration record set

\begin{tabular}{|c|c|c|}
\hline Earthquake & Magnitude & Number of record pairs \\
\hline 1974 Lima (Peru) & 8.1 & 2 \\
\hline 1985 Valparaiso (Chile) & 7.8 & 4 \\
\hline 1985 Michoacan (Mexico) & 8.0 & 4 \\
\hline 1992 Landers (USA) & 7.3 & 3 \\
\hline 1999 Kocaeli (Turkey) & 7.5 & 2 \\
\hline 2003 Hokkaido (Japan) & 8.3 & 6 \\
\hline 2008 Wenchuan (China) & 7.9 & 8 \\
\hline 2010 Maule (Chile) & 8.8 & 3 \\
\hline 2010 E1 Mayor Cucapah (USA) & 7.2 & 25 \\
\hline 2011 Tohoku (Japan) & 9.0 & \\
\hline
\end{tabular}

from the PEER NGA-West2 database that belonged to a horizontal record pair, both of whose components had $D s_{5-75}$ lesser than $25 \mathrm{~s}$. The spectral ordinates of each short duration record were then scaled by a factor $k=\bar{L} / \bar{S}$, such that the mean of the spectral ordinates of the scaled record $(k \bar{S})$ was equal that of the long duration record $(\bar{L})$. A constraint of $k \leq 5$ was imposed to avoid the scaling of low intensity records by large factors. The sum of squared errors $(S S E)$ used to quantify the error between the two response spectra was then computed as

$$
S S E=\sum_{i=1}^{120}\left(L_{i}-k S_{i}\right)^{2}
$$

Among all candidate short duration records that had not already been selected, the one with the lowest sum of squared errors was chosen. Figure 3 shows a comparison of the response spectra and time histories of one such spectrally equivalent, long and short duration record pair. This resulted in the creation of a short duration set with a geometric mean $D s_{5-75}$ of $6 s$, with each of the 146 records having a spectrally equivalent match in the long duration set. As a point of reference, $6 s$ is the predicted median $D s_{5-75}$ for a magnitude 6.4 earthquake, at a source distance of $50 \mathrm{~km}$, using Abrahamson and Silva (1996). The distribution of $D s_{5-75}$ for the short duration set is shown in the lower portion of Figure 2. By selecting these with matching spectral shapes, it is hypothesized that variations in collapse capacity obtained using the two record sets can be attributed to the difference in their ground motion durations. It is later verified that the adopted selection procedure did not introduce 
any significant biases with respect to other ground motion characteristics that may influence the calculated collapse capacity as well. Detailed information about the two record sets is available in a digital appendix to this paper: http://purl.stanford.edu/gq974qw0332.

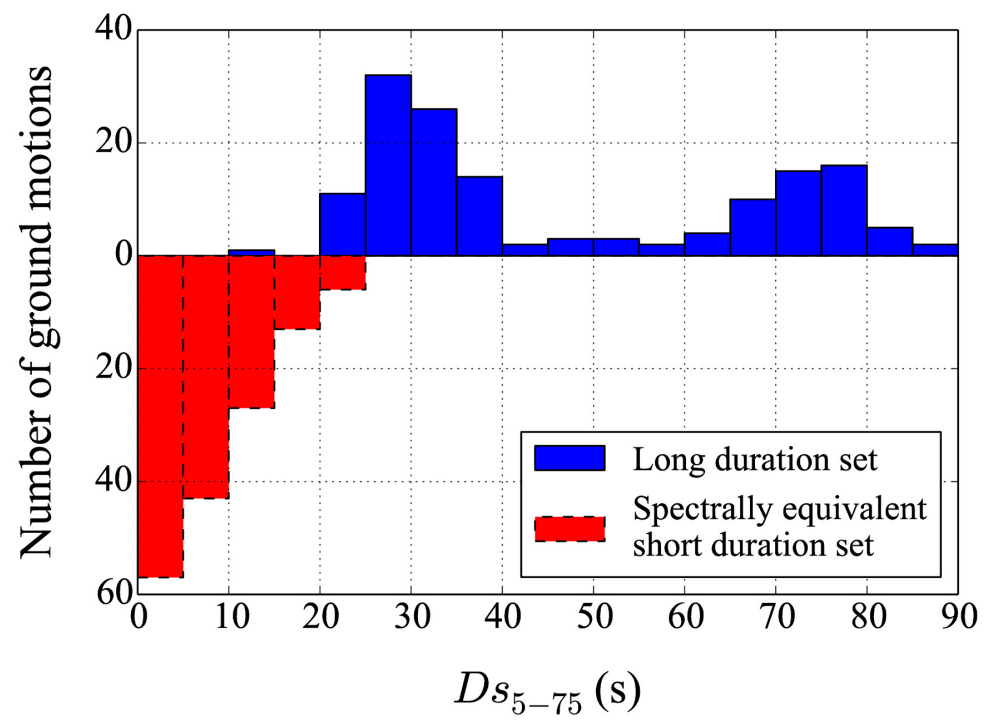

Figure 2. Distribution of $D s_{5-75}$ of the records in the spectrally equivalent, long and short duration record sets.

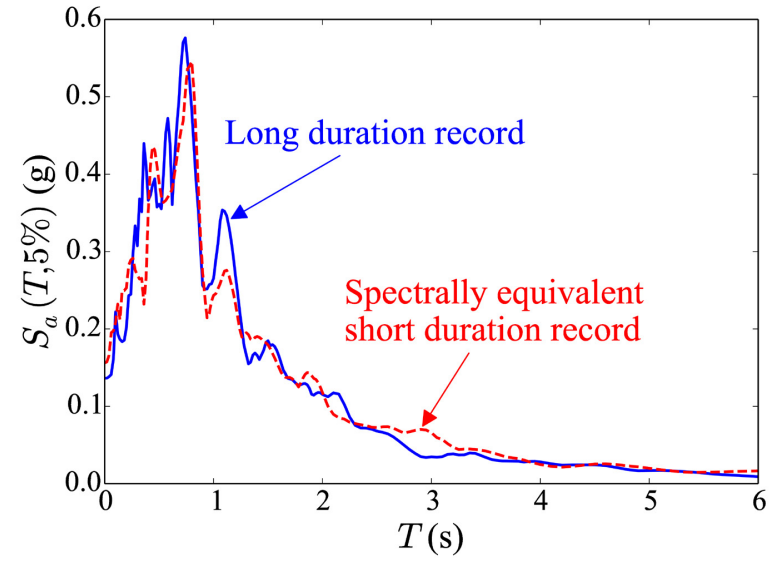

(a)

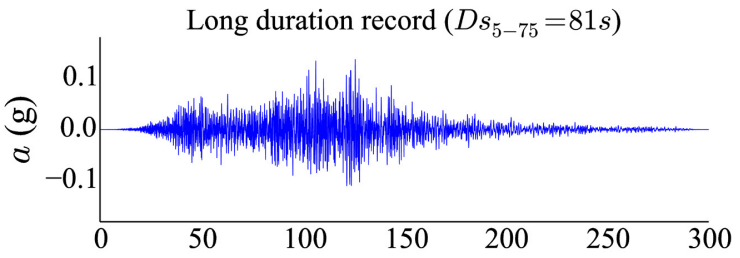

Spectrally equivalent short duration record $\left(D s_{5-75}=14 s\right)$

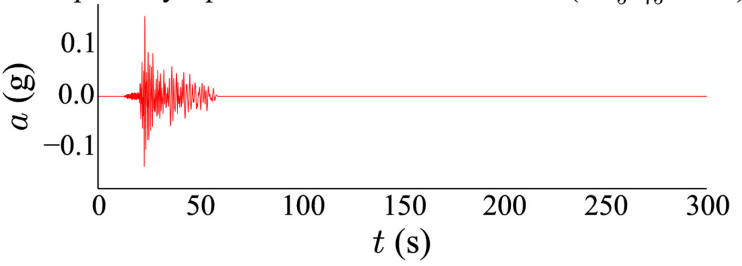

(b)

Figure 3. Comparison of the (a) response spectra and (b) time histories of a spectrally equivalent, long and short duration record pair. The long duration record is from the 2011 Tohoku earthquake, recorded at the Kaminoyama (YMT011) station. The short duration record is from the 2004 Chuetsu earthquake, recorded at the Joetsu City (65019) station, scaled by a factor of 0.74 . 


\section{NON-LINEAR DYNAMIC ANALYSIS OF A STEEL MOMENT FRAME MODEL}

A modern, five-story steel special moment frame, based on an actual building located in San Francisco (also used in FEMA 2014), was modeled and analyzed to assess the influence of duration. A schematic of the two-dimensional model, which was analyzed using OpenSees rev. 5184 (McKenna et al. 2006), is shown in Figure 4. The beams and columns of the frame were modeled using linear elastic elements, with zero-length plastic hinges located at the ends of each column and the reduced beam section (RBS) cuts near the ends of each beam. The hysteretic behavior of the plastic hinges was modeled using the Modified Ibarra-MedinaKrawinkler bilinear model that includes a post-peak negative stiffness branch of the backbone curve to capture in-cycle deterioration, as well as an algorithm that cyclically deteriorates strength and stiffness based on the cumulative hysteretic energy dissipated (Ibarra et al. 2005). Finite panel zones were modeled, with their shear deformations represented by a trilinear backbone curve. The contribution of the adjacent gravity system to the destabilizing $P-\Delta$ effect was modeled using a pin-connected leaning column. The calculated fundamental period of the structure is $1.6 \mathrm{~s}$.

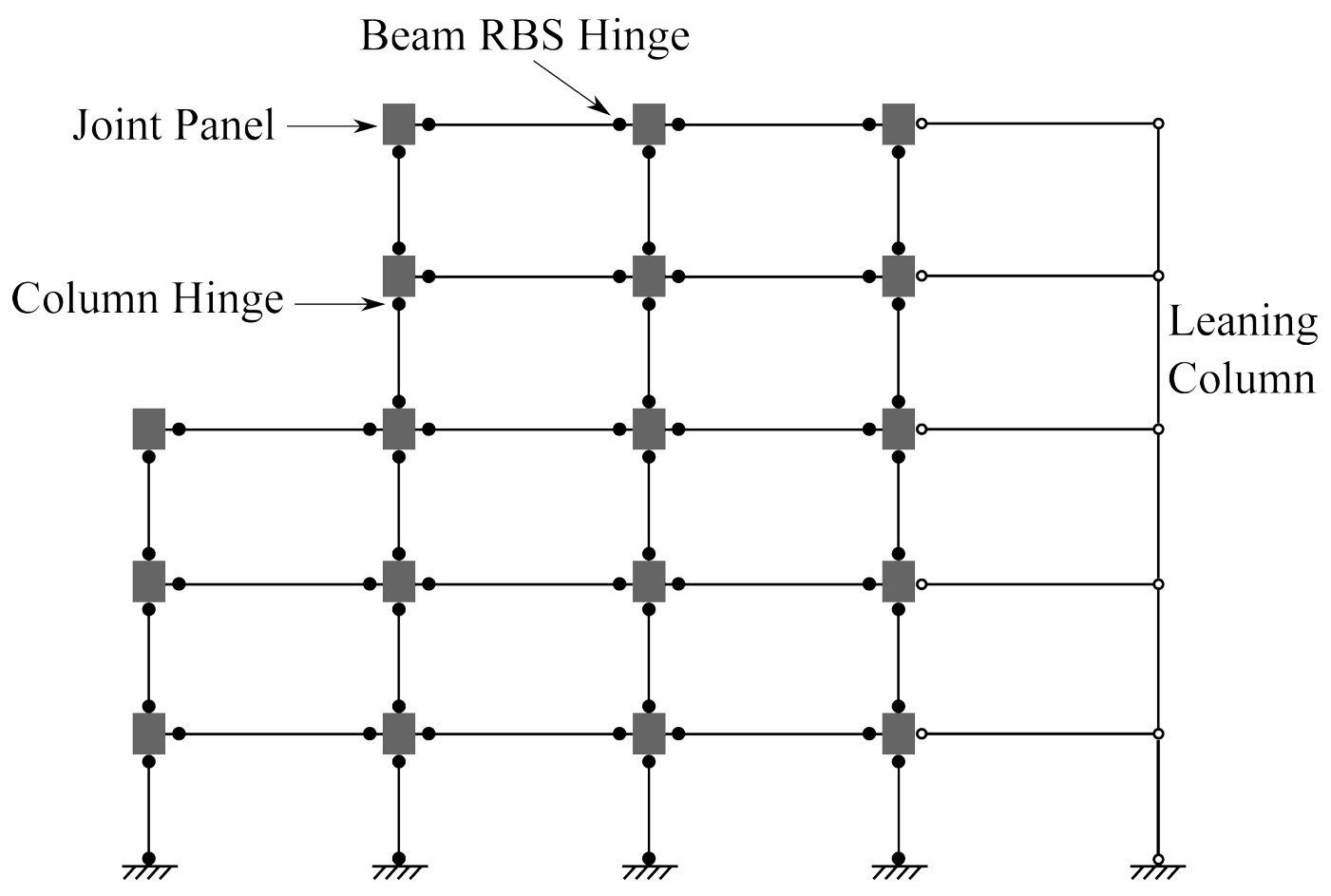

Figure 4. Schematic of the five-story steel special moment frame model. 
During each analysis, the peak story drift ratio $(S D R$, calculated as the maximum lateral story drift ratio over all the stories and the entire duration of shaking) was monitored, and an unbounded increase in peak $S D R$, above a threshold of $0.10 \mathrm{rad}$, was used as andication of structural collapse. Numerical time integration was performed using the explicit central difference scheme, since it was found to be more robust than implicit numerical integration schemes, which sometimes failed to converge at large drifts.

The collapse fragility curves resulting from incremental dynamic analyses conducted using the spectrally equivalent, short and long duration record sets are shown in Figure 5. The median collapse capacities estimated using the short and long duration record sets are $0.92 \mathrm{~g}$ and $0.65 \mathrm{~g}$, respectively. Since the record sets are spectrally equivalent, the $29 \%$ decrease in estimated median collapse capacity is attributed to the difference in ground motion durations. The estimated probability of collapse at the MCER level $\left(S_{a}(1.6 s, 5 \%)=\right.$ $0.41 \mathrm{~g}$ in this case) is about seven times larger using the long duration set than the short duration set (collapse probability of $11 \%$ using the long duration set vs. 1.4\% using the short duration set). When integrated with the seismic hazard curve corresponding to the location of the building in San Francisco, the mean annual frequencies of collapse computed using the short and long duration record sets are $0.92 \times 10^{-4}$ and $2.8 \times 10^{-4}$ respectively, indicating a three-fold increase in collapse risk when using the long duration set. Although it is unrealistic to expect ground motions like those contained in the long duration record set in San Francisco, these numbers serve to illustrate how collapse risk can be influenced by ground motion duration.

The geometric means of the $I D A$ curves for both record sets, relating peak $S D R$ to ground motion intensity, are plotted in Figure 6. The curves begin to diverge at a peak $S D R$ value of about $0.03 \mathrm{rad}$, which coincides with the point where the steel beam hinges reach their peak strengths and begin to strain-soften. This trend has also been observed by the authors in other structural models analyzed in related research (though not presented here), indicating that the influence of ground motion duration on peak $S D R$ is observed only at intensity levels large enough to produce non-linear deformations that extend into the post-peak softening range of inelastic response. This observation helps reconcile the results of this study with the those of many previous studies summarized in Hancock and Bommer (2006), which used numerical models that did not incorporate deterioration and $P-\Delta$ effects, and hence, found no influence of duration on peak deformation demands. An important implication of this is that 


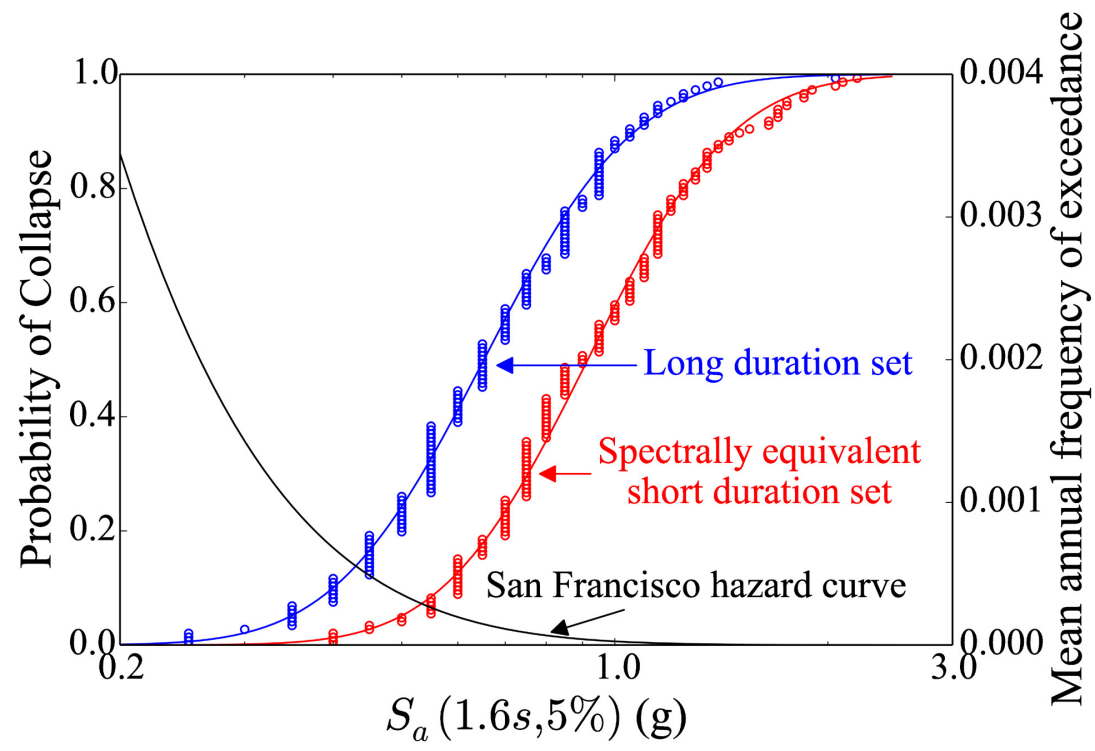

Figure 5. Collapse fragility curves estimated using the spectrally equivalent, long and short duration record sets, and the hazard curve corresponding to the location of the building in San Francisco.

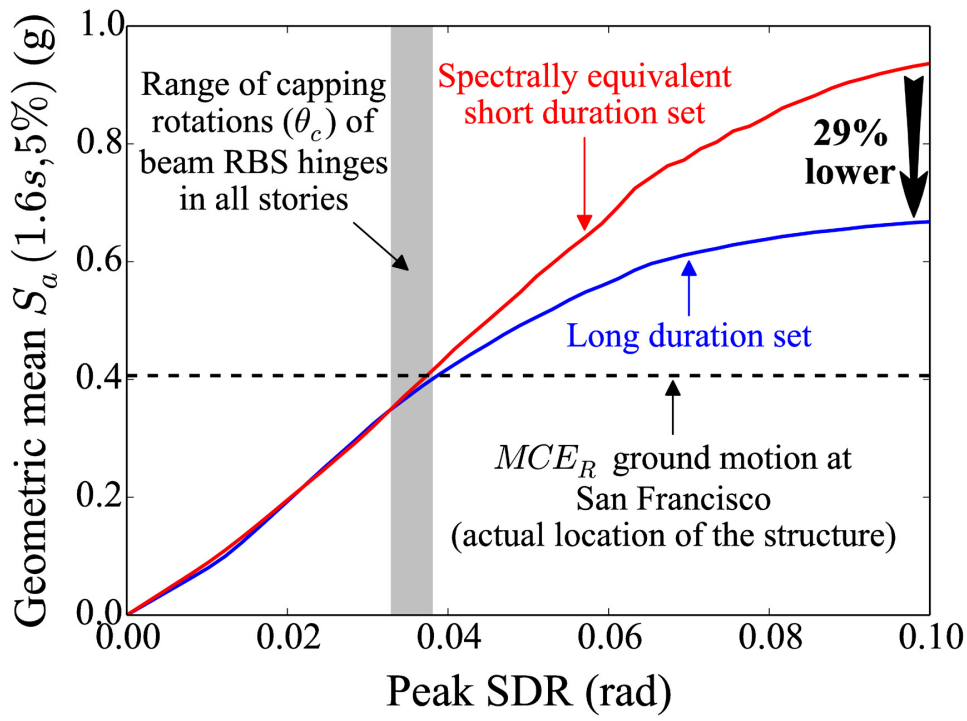

Figure 6. Geometric mean IDA curves of the spectrally equivalent, long and short duration record sets.

although long duration ground motions predict lower collapse capacities, the effect of duration on peak global deformations will not be detected when analyzing new building designs at or below MCER intensities (MCER level in this case is $S_{a}(1.6 s, 5 \%)=0.41 \mathrm{~g}$ ), as is standard practice when non-linear analyses are used for building design (Deierlein et al. 
2010; PEER 2010a). Therefore, methods that consider the influence of ground motion duration on collapse safety will need to go beyond analyses using ground motions scaled to $\mathrm{MCE}_{\mathrm{R}}$ intensities. Either non-linear analyses will need to be conducted at higher ground motion intensities, where duration-sensitive structural deterioration and $P-\Delta$ effects are captured, or alternatively, adjustment factors for design strength and/or ductility requirements may need to be applied to maintain sufficient margins of safety against collapse, at sites where long duration ground motions are expected.

Shown in Figure 7 is a log-log plot of the collapse capacity, $S_{a}(1.6 s, 5 \%)$, versus $D s_{5-75}$, for each ground motion. Although the decreasing trend in collapse capacity with $D s_{5-75}$ is evident from the plot, this representation of the data does not utilize information about the spectral equivalence of corresponding long and short duration record pairs. Therefore, an alternative representation of the data, in terms of two new parameters: Collapse Capacity Ratio and D $s_{5-75}$ Ratio is presented. Collapse Capacity Ratio or $C C R$ of a spectrally equivalent record pair is defined as the ratio of the collapse capacities produced by the long and short duration records within each pair. Similarly, the $D s_{5-75}$ Ratio of a spectrally equivalent record pair is defined as the ratio of the $D s_{5-75}$ of the long and short duration records. As shown in Figure 8, plotting $\ln (C C R)$ against $\ln \left(D s_{5-75}\right.$ Ratio $)$ for all 146 spectrally equivalent record pairs confirms that within each spectrally equivalent record pair, on average, the longer the duration of one ground motion with respect to the other, the lower the collapse capacity it predicts. As illustrated by the values highlighted in the figure, a ground motion with 2 times the duration of another predicts a $10 \%$ lower collapse capacity on average. Similarly, a ground motion with 30 times the duration of another predicts a $50 \%$ lower collapse capacity on average.

A few other observations can be made from the plot in Figure 8. The $p$-value (Kutner et al. 2004) of the slope of the least squares regression line (from a 1 -sided $t$-test) is $1.0 \times 10^{-8}$. This low $p$-value indicates that the influence of duration on collapse capacity is statistically significant. The y-intercept of the least squares regression line is 1.08 , with a $p$-value of 0.35 (from a 2 -sided $t$-test). This large $p$-value implies that if two records have identical spectral shapes and durations represented by $D s_{5-75}$, they predict the same collapse capacity on average. This indicates that there were no statistically significant biases introduced during the record selection process with respect to other unaccounted ground motion characteristics that could influence collapse capacity. The coefficient of determination $\left(R^{2}\right)$ from the regression 
analysis is 0.20 , which implies that taking into account the $D s_{5-75}$ of the ground motions decreased the variance in $\ln (C C R)$ by $20 \%$. This $R^{2}$ statistic is a measure of the efficiency of $D s_{5-75}$ in predicting $\ln (C C R)$ and is used to compare the efficiencies of alternative duration metrics.

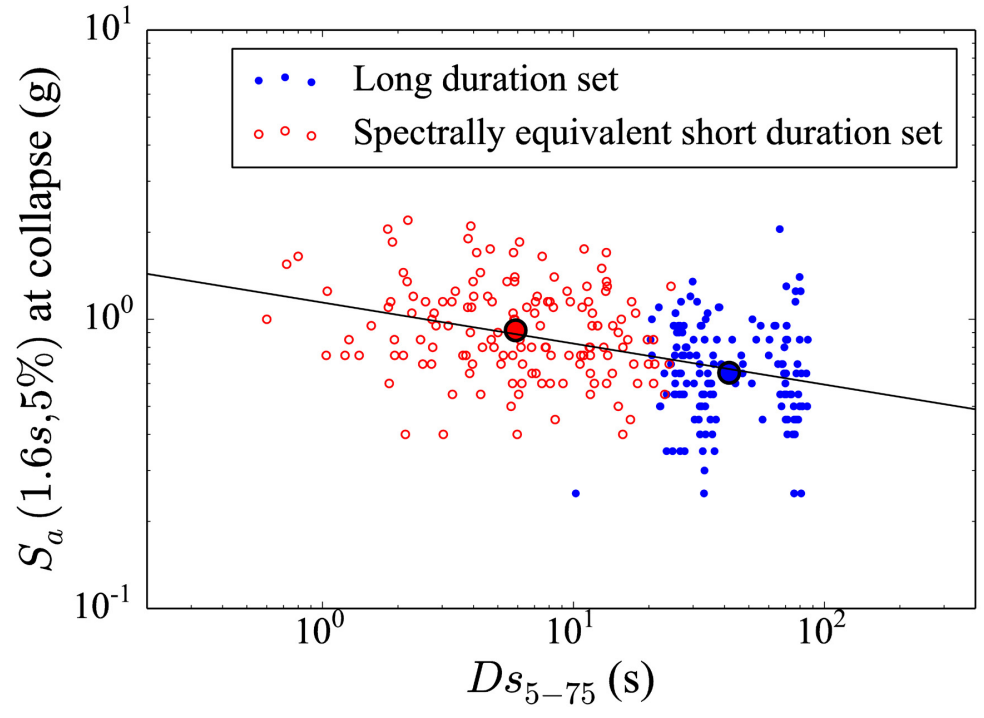

Figure 7. Log-log plot of collapse capacity vs. $D s_{5-75}$ (the two large circles represent the geometric mean collapse capacity and geometric mean $D s_{5-75}$ of all ground motions in the corresponding set).

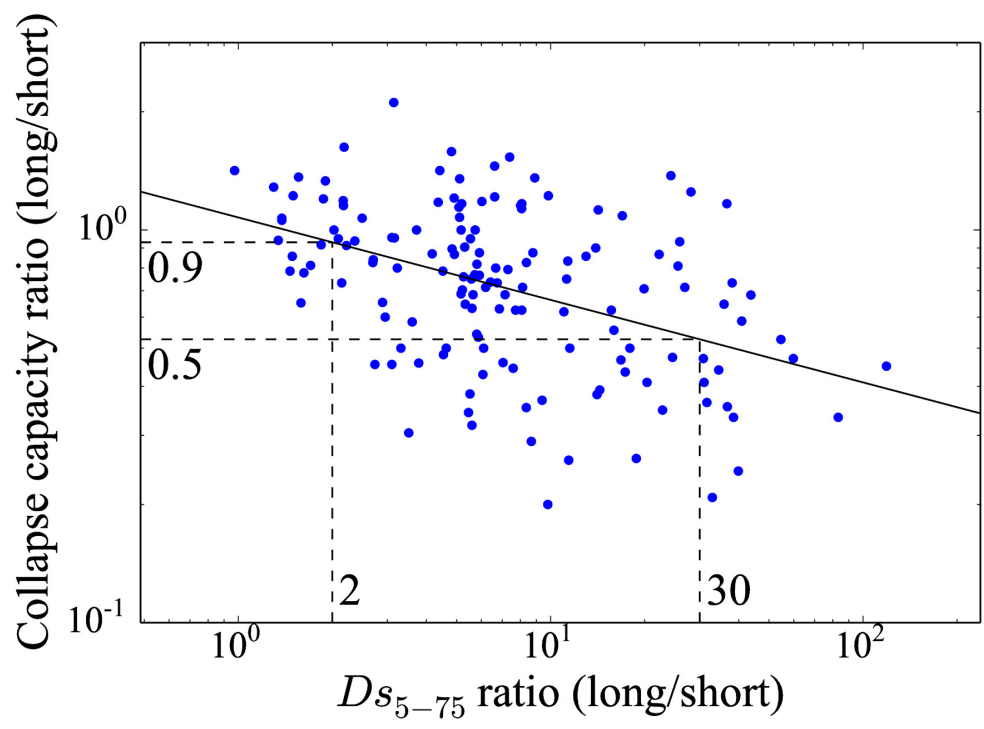

Figure 8. Log-log plot of Collapse Capacity Ratio vs. $D s_{5-75}$ Ratio with the least squares regression line 


\section{ANALYSIS OF DURATION METRICS}

A number of metrics exist, other than $D s_{5-75}$, that could be used to quantify ground motion duration (Bommer and Martinez-Pereira 1999). This study considers the following, which are evaluated relative to $D s_{5-75}$ :

- 5-95\% significant duration $\left(\boldsymbol{D} \boldsymbol{s}_{5-95}\right)$ : The time interval over which $5 \%$ to $95 \%$ of the integral $\int_{0}^{t_{\max }} a(t)^{2} d t$ is accumulated (Trifunac and Brady 1975).

- $0.05 g$ bracketed duration $\left(D b_{0.05}\right)$ : The time elapsed between the first and last excursions of the accelerogram above a threshold of $\pm 0.05 g$ (Bolt 1973). Higher or lower thresholds may be used, however, $0.05 \mathrm{~g}$ is judged to be a reasonable value for evaluating ground motions that cause damage to engineered structures.

- Arias intensity $\left(\boldsymbol{I}_{\boldsymbol{A}}\right)=\frac{\pi}{2 g} \int_{0}^{t_{\max }} a(t)^{2} d t$ : A measure of the energy contained in the accelerogram and a hybrid metric of duration and intensity (Arias 1970). It is expected to be correlated to the duration of strong shaking since it involves integration over time (Kayen and Mitchell 1997).

- Cumulative absolute velocity $(\boldsymbol{C A V})=\int_{0}^{t_{\max }}|a(t)| d t$ : Another hybrid metric (Benjamin 1988) that is expected to be more correlated to the duration of an accelerogram than its intensity, when compared to Arias intensity, since it involves integration of a lower power of $a(t)$ over time.

- $\boldsymbol{I}_{\boldsymbol{D}}=\frac{\int_{0}^{t_{\max } a(t)^{2} d t}}{P G A \times P G V}:$ A dimensionless metric of duration proposed by Cosenza and Manfredi (1997), computed as the integral of $a(t)^{2}$ normalized by the peak ground acceleration and velocity.

A duration metric is considered efficient (Luco and Cornell 2007) if it produces a large decrease in the variance of $\ln (C C R)$, i.e., produces a large $R^{2}$ statistic in a regression analysis similar to the one presented in the previous section. In fact, any ground motion metric that results in a significant decrease in the variance of $\ln (C C R)$ could be considered an efficient predictor of collapse capacity. This motivates the consideration of hybrid metrics like $I_{A}$ and CAV.

The efficiencies of the duration metrics defined above are compared by plotting $\ln (C C R)$ against $\ln ($ Duration Ratio) or $\ln (D R)$, similar to Figure 8 . There is, however, some ambiguity in the definition of a few of the duration metrics defined above when records are 
scaled to cause structural collapse. This ambiguity arises because the $D b_{0.05}, I_{A}$, and $C A V$ of a ground motion change as it is scaled. Thus, in this context, the duration measure is not unique, and could, for example, refer to either the duration of the original ground motion, or of the ground motion scaled to the collapse intensity, following IDA procedure. Both interpretations are considered in the following comparison.

The $R^{2}$ statistics for the duration metrics are summarized in Table 2, where values for $D b_{0.05}, C A V$, and $I_{A}$ are reported both for the original and scaled ground motions. The values in the first $\left(D s_{5-75}\right)$ column are for the record sets discussed previously; values in the other columns are for alternative record sets that are discussed below. In the $D s_{5-75}$ column, all duration metrics computed from the unscaled ground motions have $R^{2}$ values between 0.13 and 0.20 , and the regression analyses exhibit similar decreasing trends between $\ln (C C R)$ and $\ln (D R)$ as observed for the $D s_{5-75}$ data in Figure 8. The $D b_{0.05}, C A V$, and $I_{A}$ metrics computed from the scaled ground motions (shaded rows in Table 2), however, do not share this trend. For the scaled $C A V$ and $I_{A}, \ln (C C R)$ is found to increase, rather than decrease, with $\ln (D R)$. Figure 9 shows the different regression lines obtained when $I_{A}$ is computed from the original and scaled records. This difference is due to the inherent positive correlation of these scaled duration metrics to the estimated collapse capacity. By definition, $D b_{0.05}, C A V$, and $I_{A}$ increase as the ground motion is scaled up, so if a ground motion is scaled up by a factor $x(x>1), C A V$ increases by a factor of $x, I_{A}$ increases by a factor of $x^{2}$, and $D b_{0.05}$ increases, though in a less predictable manner. This variation in the duration metrics with scaling, coupled with the fact that the short duration records need to be scaled to higher intensities to cause structural collapse than the long duration records, is the cause of the inconsistent trends. Apart from their self-fulfilling correlation to the estimated collapse capacity, duration metrics that are influenced by scaling pose the more obvious problems of having ambiguous values. One could imagine, for example, that if durations were defined at the scaled collapse intensity, then the duration metrics would be structure-dependent and determinable only after conducting an IDA. Thus, duration metrics that do not vary with scaling, such as significant duration and $I_{D}$, are better suited than others to analysis applications where ground motions are routinely scaled, such as conducting IDA.

The results discussed thus far are based on pairs of long and short duration ground motions that were chosen based on their $D s_{5-75}$ values. To verify that the results were not biased by this initial selection, the same analyses were repeated using long and short duration 
Table 2. Summary of $R^{2}$ statistics for all considered duration metrics computed using three long duration record sets chosen based on $D s_{5-75}, D s_{5-95}$, and $D b_{0.05}$ and their corresponding spectrally equivalent, short duration record sets

\begin{tabular}{|c|c|c|c|}
\hline \multirow{2}{*}{ Duration Metric } & \multicolumn{3}{|c|}{$\boldsymbol{R}^{\mathbf{2}}$ statistic } \\
\cline { 2 - 4 } & $\boldsymbol{D} \boldsymbol{s}_{\mathbf{5 - 7 5}}$ set & $\boldsymbol{D s}_{\mathbf{5 - 9 5}}$ set & $\boldsymbol{D b}_{\mathbf{0 . 0 5}}$ set \\
\hline 5-75\% significant duration $\left(D s_{5-75}\right)$ & 0.20 & 0.18 & 0.09 \\
\hline 5-95\% significant duration $\left(D s_{5-95}\right)$ & 0.16 & 0.16 & 0.06 \\
\hline 0.05 g bracketed duration $\left(D b_{0.05}\right)$ & 0.13 & 0.19 & 0.08 \\
\hline$I_{D}$ (Cosenza and Manfredi 1997$)$ & 0.17 & 0.16 & 0.10 \\
\hline Cumulative absolute velocity $(C A V)$ & 0.20 & 0.18 & 0.09 \\
\hline Arias intensity $\left(I_{A}\right)$ & 0.17 & 0.17 & 0.06 \\
\hline$D b_{0.05}$ when scaled to cause collapse & 0.09 & 0.05 & 0.04 \\
\hline$C A V$ when scaled to cause collapse & 0.01 & 0.00 & 0.04 \\
\hline$I_{A}$ when scaled to cause collapse & 0.32 & 0.20 & 0.33 \\
\hline
\end{tabular}

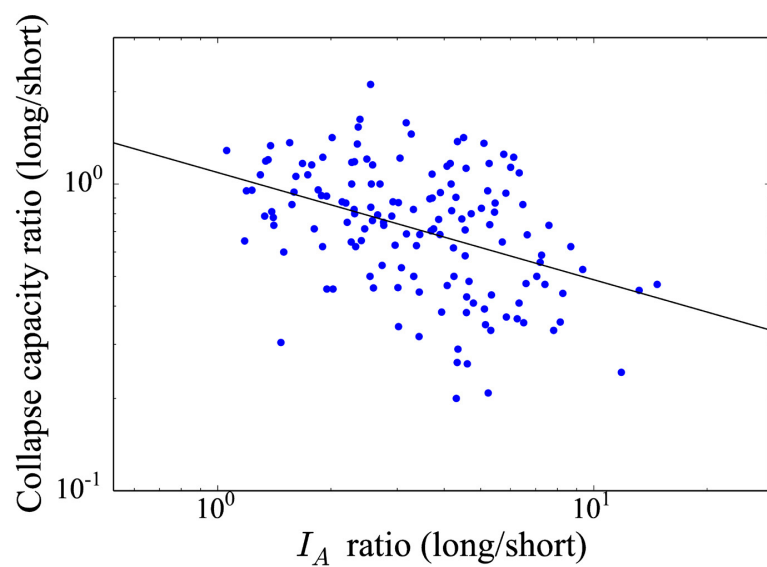

(a)

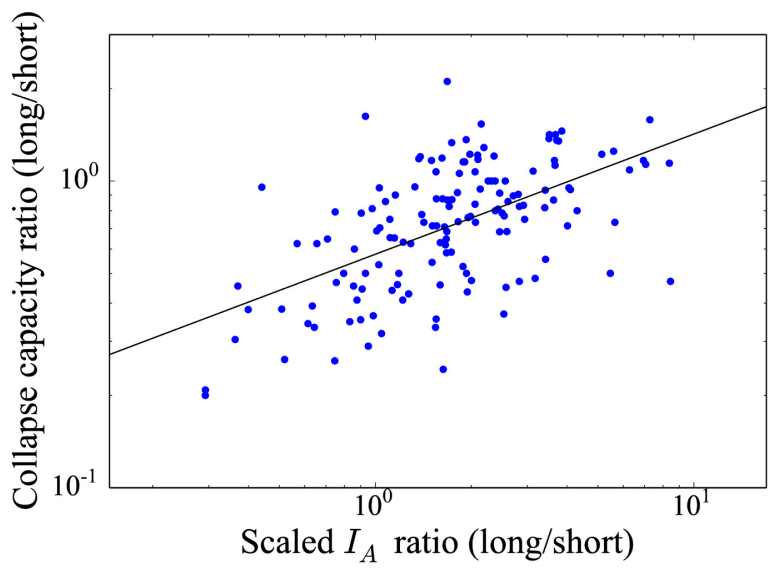

(b)

Figure 9. Log-log plots of Collapse Capacity Ratio vs. Duration Ratio, with least squares regression lines, where duration is represented by Arias intensity computed (a) from the original ground motion and (b) when scaled to the collapse intensity.

record sets of roughly the same size, chosen using $D b_{0.05}$ and $D s_{5-95}$ to distinguish long from short records. Records with $D b_{0.05}$ greater than $55 s$ or $D s_{5-95}$ greater than $45 s$ were identified as long duration records. Proceeding in the same manner as before, the record sets were selected, IDAs were conducted, and regression analyses were carried out for $\ln (C C R)$ 
against $\ln (D R)$, for all the duration metrics. The trends from the two sets of analyses were found to be similar to those shown previously in Figures 8 and 9, and the $R^{2}$ statistics are summarized in the last two columns of Table 2. Although the specific values of the $R^{2}$ statistics are different for the three sets $\left(D s_{5-75}, D s_{5-95}\right.$, and $\left.D b_{0.05}\right)$, the trends between duration metrics within each set are similar.

Scalar intensity measures (IMs), such as $C A V, I_{A}$, and source magnitude, which implicitly incorporate information about the amplitude and duration of a ground motion, are often used in geotechnical earthquake engineering to assess the deformation and liquefaction potential of soil deposits (Kayen and Mitchell 1997; Kramer and Mitchell 2006; Sideras and Kramer 2012). For structural analysis and performance assessment, however, a more explicit description of the site hazard in terms of a vector of response spectral ordinates is preferred since the wide range of engineering demand parameters $(E D P \mathrm{~s})$ considered for different structures, are each sensitive to different components of the vector. This vector $I M$ is used to define a target response spectrum, such as a conditional spectrum, which quantifies a target intensity and response spectral shape for selecting ground motions. Where a duration metric is to be added to this vector $I M$, it should provide non-redundant information that is not already quantified by the other components of the vector. It should, therefore, be independent of ground motion intensity. Among the duration metrics described above, a statistical analysis of records collected for this study confirm that $D b_{0.05}, C A V$, and $I_{A}$ are all strongly correlated to common $I M$ s like $P G A, P G V$, and $S_{a}(1 s, 5 \%)$. This lack of independence implies that they would not be effective duration metrics to add to a vector IM.

To further explore the suitability of alternative duration metrics, three additional long duration record sets based on $I_{D}, C A V$, and $I_{A}$ were developed. An analysis of the selected records revealed that screening ground motions using $C A V$ and $I_{A}$ can lead to the unintended selection of ground motions with large acceleration values over a short time interval, i.e. ground motions with large $C A V$ and $I_{A}$ values, but small durations of strong shaking. In addition, certain duration metrics can lead to the selection of ground motions with biased spectral shapes. This is illustrated in Figure 10, where the geometric mean response spectra of all six long duration sets, created by screening using the six duration metrics, are compared. The response spectra are all normalized to have $S_{a}(1.6 s, 5 \%)=1 g$, and are plotted against two common benchmark ground motion sets: the FEMA P695 far field set (FEMA 2009) and PEER Transportation set 2 (Baker et al. 2011). The record sets screened 
using $I_{D}, C A V$, and $I_{A}$ (Figure 10(a)) are observed to have significantly different spectral shapes, when compared to the benchmark sets and the record sets screened using $D s_{5-75}$, $D s_{5-95}$, and $D b_{0.05}$ (Figure 10(b)).

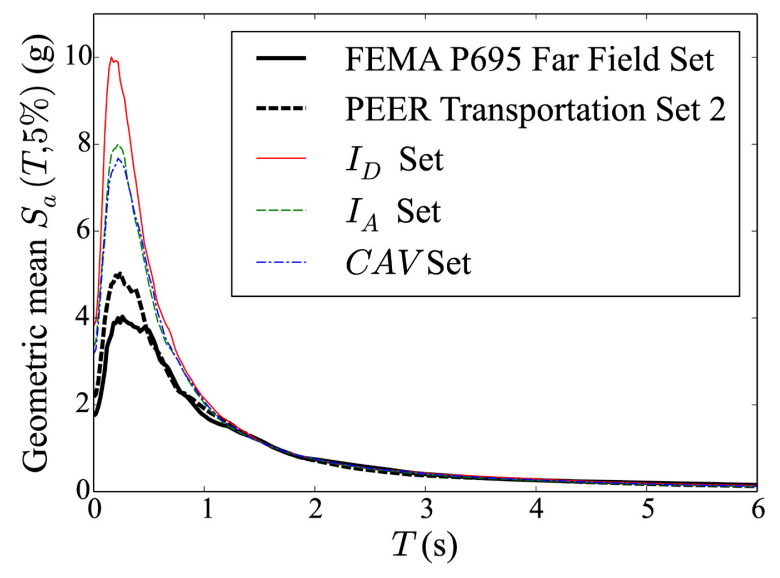

(a)

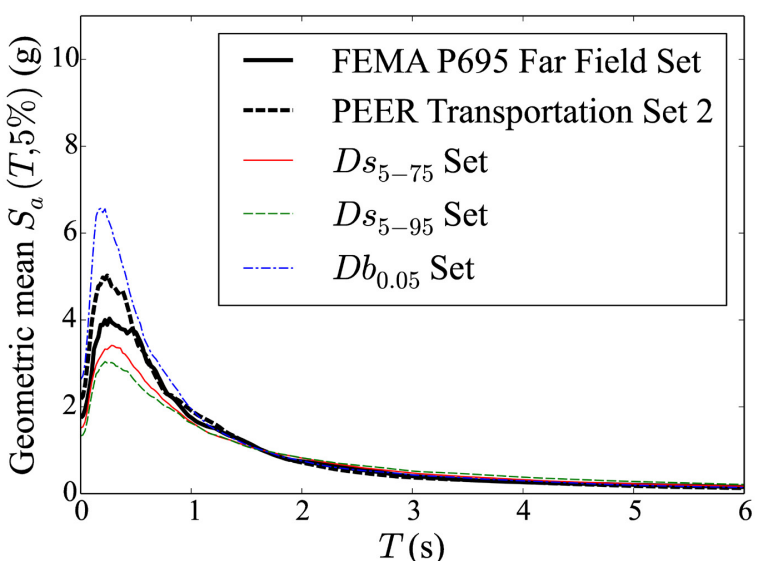

(b)

Figure 10. Comparison of the geometric mean response spectra of the long duration sets screened using all six duration metrics, to those of benchmark ground motion sets, scaled to have $S_{a}(1.6 s, 5 \%)=1 \mathrm{~g}$.

Table 3. Comparison of the characteristics of the duration metrics considered

\begin{tabular}{|c|c|c|c|c|c|}
\hline Desired Characteristic & 莬 & 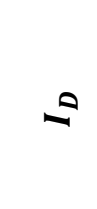 & 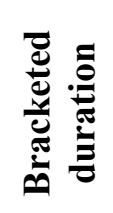 & 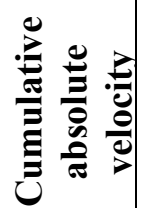 & 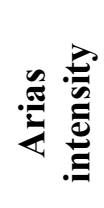 \\
\hline $\begin{array}{l}\text { Is not strongly correlated to common intensity } \\
\text { measures }\end{array}$ & $\checkmark$ & $\sqrt{ }$ & $\mathbf{x}$ & $\mathbf{x}$ & $\mathbf{x}$ \\
\hline Is not a hybrid metric of intensity and duration & $\checkmark$ & $\checkmark$ & $\checkmark$ & $x$ & $\boldsymbol{x}$ \\
\hline Is unaffected by scaling & $\checkmark$ & $\checkmark$ & $x$ & $x$ & $x$ \\
\hline $\begin{array}{l}\text { Is an efficient predictor of structural collapse capacity } \\
\left(R^{2} \text { statistic from Table } 2 \text { is not too low }\right)\end{array}$ & $\checkmark$ & $\checkmark$ & $\checkmark$ & $\checkmark$ & $\checkmark$ \\
\hline $\begin{array}{l}\text { All ground motions with large values of the metric } \\
\text { actually have long intervals of strong shaking }\end{array}$ & $\checkmark$ & $\checkmark$ & $\checkmark$ & $x$ & $x$ \\
\hline $\begin{array}{l}\text { Ground motions with large values of the metric do not } \\
\text { have unusual spectral shapes }\end{array}$ & $\checkmark$ & $x$ & $\checkmark$ & $x$ & $x$ \\
\hline
\end{tabular}


Finally, a qualitative comparison of the considered duration metrics is summarized in Table 3, where the metrics are judged according to several practical criteria. Based on this comparison, significant duration is identified as the preferred duration metric for use in ground motion selection for structural performance assessment. The choice between 5-75\% and $5-95 \%$ significant duration is less clear, though in the case of the structural models considered in this study, the authors found 5-75\% significant duration to be slightly more robust since it consistently produced higher $R^{2}$ values in Table 2. As noted by Kempton and Stewart (2006), since 5-75\% significant duration is correlated to the duration of body wave arrivals alone, and 5-95\% significant duration is also influenced by the later surface wave arrivals, the choice between the two is expected to be structure dependent. Nevertheless, the procedure developed in this study can be used to assess the efficiency of any other duration metric in predicting structural collapse capacity.

\section{SENSITIVITY ANALYSIS OF THE EFFECT OF DURATION TO THE PARAMETERS OF A REINFORCED CONCRETE BRIDGE PIER MODEL}

To investigate the interaction of structural characteristics with the effect of ground motion duration, a bridge pier structure was employed, since in contrast to the larger steel frame model, its fewer degrees of freedom facilitated systematic variation of structural model parameters. The base model is of a reinforced concrete bridge pier that was previously tested as part of the Concrete Column Blind Prediction Contest (PEER 2010b). The structure was modeled in OpenSees rev. 5184 (McKenna et al. 2006) using a linear elastic element connected to the base through a zero-length plastic hinge, following the Modified IbarraMedina-Krawinkler peak-oriented hysteretic model (Ibarra et al. 2005). Similar to the bilinear hysteretic model used in the five-story moment frame model, the peak-oriented model combines a post-peak negative stiffness branch of the backbone curve to capture incycle strain-softening and a cyclic model to capture strength and stiffness deterioration based on the cumulative hysteretic energy dissipated. The destabilizing $P-\Delta$ effect of gravity loads was incorporated in the model. A schematic of the model is shown in Figure 11(a). The parameters of the model were calibrated to experimental measurements, the results of which are compared in Figure 11(b). Its fundamental period is $1.2 \mathrm{~s}$.

The spectrally equivalent, long and short duration record sets chosen based on $D s_{5-75}$ were used to conduct IDA on the base model. Collapse was indicated by an unbounded increase in peak chord rotations, above a threshold of $0.16 \mathrm{rad}$. The percentage decrease in 


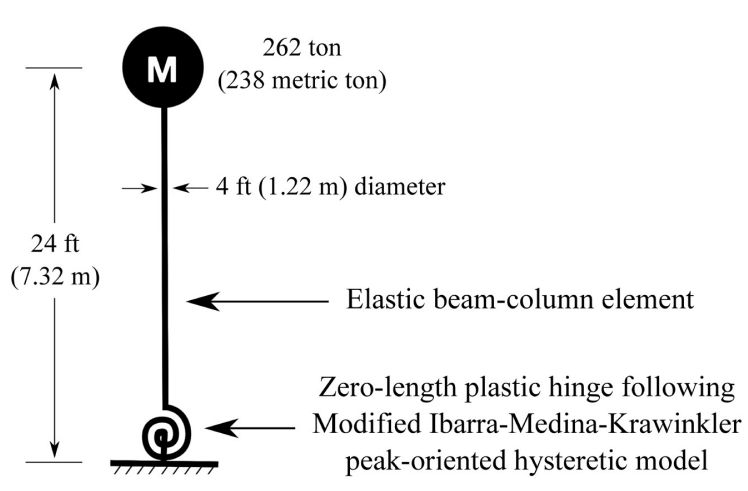

(a)

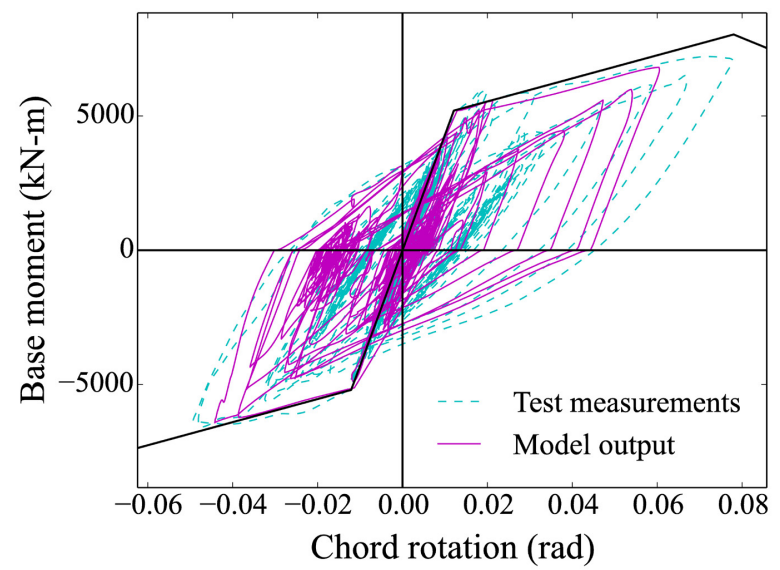

(b)

Figure 11. Reinforced concrete bridge pier: (a) Model schematic. (b) Calibration of model to test measurements.

the median collapse capacity estimated by the long duration set, with respect to the short duration set, is $17 \%$. This is in contrast to a decrease of $29 \%$ reported previously for the moment frame.

To examine how the response of the bridge pier would vary depending on design parameters that control its strength, stiffness, or deformation capacity, the sensitivity of the effect of duration to two model parameters is examined. The two model parameters are $\gamma$ and $\theta_{p}$, both of which are expected to influence the cyclic deterioration and collapse response. The first parameter, $\gamma$, is a dimensionless factor used to define the rate of cyclic deterioration in the structure. The deterioration algorithm of the Modified Ibarra-Medina-Krawinkler hysteretic model first defines the reference hysteretic energy dissipation capacity of the structure, $E_{t}$, as

$$
E_{t}=\gamma M_{y} \theta_{y}
$$

where $M_{y}$ is the yield moment and $\theta_{y}$ is the yield chord rotation of the structure. Thereafter, the structure's strength is deteriorated after every hysteretic excursion according to

$$
\begin{gathered}
M_{i}=\left(1-\beta_{i}\right) M_{i-1} \\
\beta_{i}=\left(\frac{E_{i}}{E_{t}-\sum_{j=1}^{i} E_{j}}\right)^{c}
\end{gathered}
$$


where $E_{i}$ is the hysteretic energy dissipated in the $i^{t h}$ excursion, $M_{i}$ is the deteriorated strength after the $i^{\text {th }}$ excursion, and $c$ is an exponent, commonly set to 1 . The larger the value of $\gamma$, the larger the reference hysteretic energy dissipation capacity of the structure, and therefore, the slower the rate of deterioration. The second parameter, $\theta_{p}$, is the plastic chord rotational capacity of the structure measured from the yield point to the peak point. The

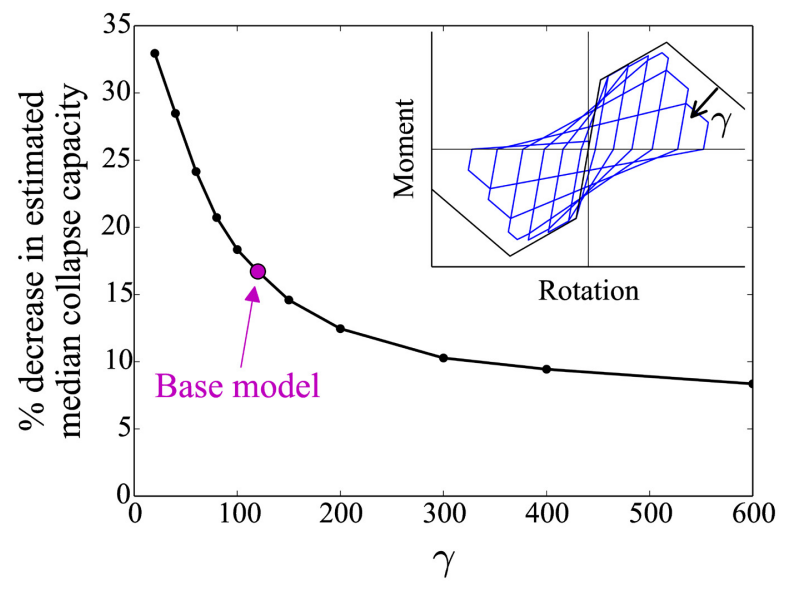

(a)

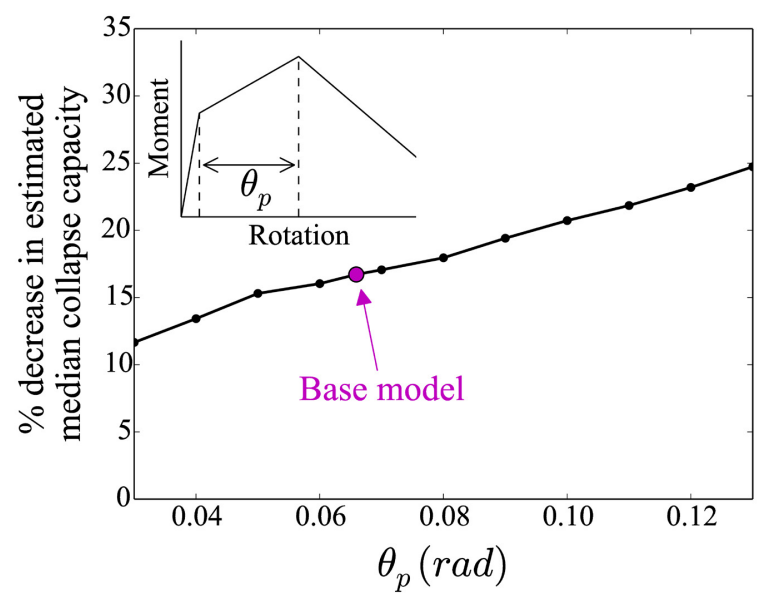

(b)

Figure 12. Sensitivity of the percentage decrease in median collapse capacity estimated by the long duration set, with respect to the short duration set, to (a) $\gamma$ : parameter controlling the rate of deterioration, and (b) $\theta_{p}$ : the plastic rotational capacity from yield to capping.

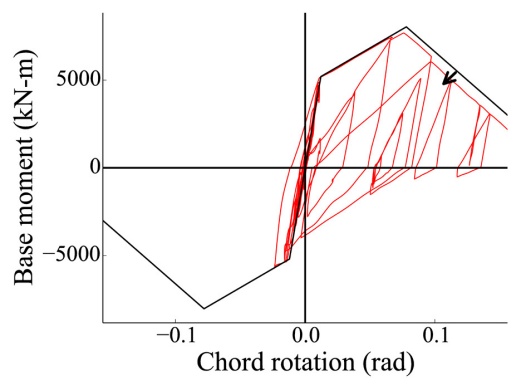

(a)

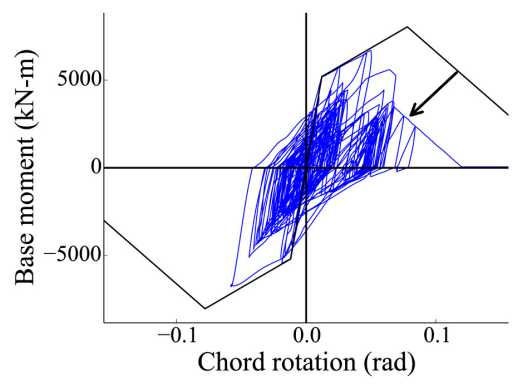

(b)

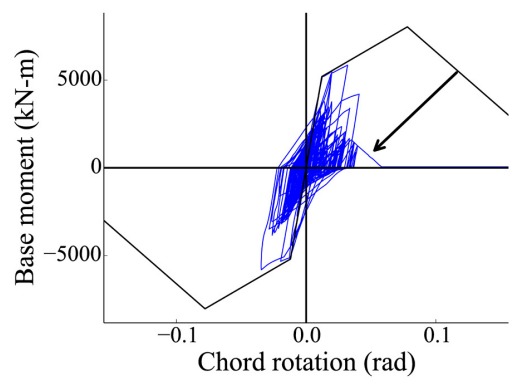

(c)

Figure 13. Hysteresis plots of the bridge pier chord rotation for (a) the base model (with $\gamma=120$ ) under a short duration ground motion, (b) the base model (with $\gamma=120$ ) under a long duration ground motion, and (c) a model with $\gamma=40$ under same long duration ground motion, when scaled to the onset of collapse. 
larger the value of $\theta_{p}$, the more ductile the structure. The ranges over which $\gamma$ and $\theta_{p}$ were varied in this study are based on the ranges of observed values of each parameter in a reinforced concrete column calibration study by Haselton et al. (2008).

The effect of duration in all subsequent analyses is quantified by the percentage decrease in median collapse capacity estimated by the long duration set, with respect to the short duration set. The variation of this difference in median collapse capacity with $\gamma$, with all other model parameters held constant, is plotted in Figure 12(a). As shown, the value of $\gamma$ for the base model is equal to 120, representing a well-confined, ductile bridge column. For lower values of $\gamma$, the influence of duration is more pronounced, with the difference in median collapse capacity increasing from $17 \%$ for the base model up to almost 33\% for columns with lower energy dissipation capacities. Under increasing $\gamma$, the difference in median collapse capacity tends to saturate at about $8 \%$. This reduced effect of duration with high $\gamma$ is intuitively expected, and is consistent with many previous studies on duration that used numerical models that did not incorporate deterioration, and hence, observed little or no effect of duration. The residual reduction in median collapse capacity of about $8 \%$ is presumably due to cyclic ratcheting effects, where the structure ultimately fails at large drifts by $P-\Delta$ effects. This so-called ratcheting effect has been observed previously by Gupta and Krawinkler (2000), and is expected to abet the collapse of a structure subjected to long duration shaking. This trend with energy dissipation appears to differ from that of a recently published study by Raghunandan and Liel (2013), the reasons for which are not obvious. The two studies are, however, not directly comparable due to differences in ground motion selection methodology, and the use of inelastic rather than elastic spectra as the ground motion intensity measure. The apparent differences point to a need for further understanding of the role of cyclic deterioration and collapse assessment methodology on the observed effect of duration.

The interaction of cyclic deterioration and duration of loading on collapse is further illustrated in Figure 13. Figures 13(a) and (b) compare the hysteretic response of the base model (with $\gamma=120$ ) under typical short and long duration ground motions respectively, scaled to the onset of collapse. Since the structure subjected to the long duration ground motion experiences a larger number of hysteretic cycles, it deteriorates more, and thus, collapses at a lower ground motion intensity when compared to the short duration ground motion. Figure 13(c) shows the hysteretic response of the model with lesser energy 
dissipation capacity (with $\gamma=40$ ) under the same long duration ground motion as Figure 13(b). Comparing Figures 13(b) and (c), the model that deteriorates faster leads to collapse at an even lower intensity.

The variation in the difference in median collapse capacity with $\theta_{p}$ is plotted in Figure 12(b). Interestingly, here there is a near linear increase in the difference in median collapse capacity with increasing rotational capacity. This again follows intuition since a non-ductile structure (with low $\theta_{p}$ ) would collapse soon after yielding, without much cyclic degradation, thus negating the influence of ground motion duration on collapse capacity. This result is consistent with the findings of Raghunandan and Liel (2013), suggesting that ground motion duration can have a more significant effect on modern, ductile structures than older, nonductile structures.

\section{CONCLUSIONS}

Ground motion duration was found to exert a statistically significant influence on structural collapse capacity. This effect was observable using numerical models that accurately characterized structural behavior at large, non-linear deformations, including the in-cycle and cyclic deterioration of strength and stiffness of structural components, and destabilizing $P-\Delta$ effects. The effect of duration was isolated from the effects of other ground motion characteristics using "spectrally equivalent" sets of long and short duration records. A set of high intensity, long duration records from large magnitude earthquakes, including the 2011 Tohoku (Japan), 2010 Maule (Chile), and 2008 Wenchuan (China) earthquakes, was assembled. Each long duration record was paired with a spectrally equivalent, short duration record. Each set contains 146 records, and the geometric mean 5$75 \%$ significant duration of the short and long duration record sets are $6 s$ and $42 s$, respectively.

Non-linear dynamic analyses of a five-story steel special moment frame revealed a $29 \%$ decrease in median collapse capacity estimated by the long duration set, compared to the short duration set. Using the seismic hazard information for the building site, this was found to correspond to a three-fold increase in the estimated mean annual frequency of collapse and a seven-fold increase in the probability of collapse at the MCER intensity. Statistics analyzing

the spectrally equivalent record pairs indicated that the larger the difference in their durations, the lower the collapse capacity predicted by the long duration record with respect 
to the short duration record. Non-linear analyses of a ductile, concrete bridge pier model showed a $17 \%$ reduction in median collapse capacity estimated by the long duration set, compared to the short duration set. The reduction in collapse capacity with increasing ground motion duration is in contrast to many previous studies that found little or no influence of duration on peak deformations, suggesting that the models employed in these prior studies may not have fully captured the deterioration of structural strength and stiffness, and/or the destabilizing $P-\Delta$ effect of gravity loads. The structures in these studies also may not have been deformed far enough into the inelastic range for them to experience significant deterioration and consequent destabilization. Parametric studies demonstrated how the influence of duration depends on ductility and deterioration parameters of the structural model. Structures exhibiting rapid cyclic deterioration and with greater deformation capacity were found to be more sensitive to duration.

The effect of duration on peak global deformations was only observed at intensity levels large enough to produce non-linear deformations that extend into the post-peak range of the plastic hinges (at story drift ratios on the order of $0.03 \mathrm{rad}$ for the steel moment frame). For new structural designs, this is likely to only occur above the MCER intensity level. Therefore, for modern, code-conforming structures, analyses conducted at or below the MCER level are not expected to detect ground motion duration effects. This is in spite of the fact that under more intense ground motions, longer duration shaking can reduce the collapse capacity. This raises concerns since the current practice of assessing structures by non-linear dynamic analyses at MCER intensities, using predominantly short duration ground motions, may lead to designs with lower margins against collapse in locations where long duration ground motions can be expected.

A comparison of duration metrics found significant duration to be the preferred duration metric for use in ground motion selection for structural performance assessment. Although 5$75 \%$ significant duration was found to be slightly more robust than $5-95 \%$ significant duration for the considered structural model, they both appear to be effective. A key consideration in this choice was that significant duration tends to be uncorrelated to ground motion intensity and response spectral shape, and thus, is convenient to consider as an additional, independent parameter in vector seismic hazard analysis. The procedure developed here can also be used to assess the efficiency of any other duration metric in predicting structural collapse capacity. This study highlights the need to consider ground 
motion duration, in addition to intensity and response spectral shape, in regions where significant hazard due to long duration shaking exists, such as locations susceptible to large magnitude, subduction zone earthquakes. Further research is warranted to assess the influence of duration on seismic risk, based on a complete characterization of the seismic hazard in such regions, including the durations of anticipated ground motions.

\section{ACKNOWLEDGEMENTS}

The authors thank Jeff Bayless and Christine Goulet for sharing scripts used to process non-NGA ground motions, Wenhao Chen for the moment frame model used in this study, and Brendon Bradley, Julian Bommer, and an anonymous reviewer for their thorough and constructive comments on the manuscript.

This work was supported by the State of California through the Transportation Systems Research Program of the Pacific Earthquake Engineering Research Center (PEER). Any opinions, findings, and conclusions or recommendations expressed in this material are those of the authors and do not necessarily reflect those of the funding agency. The numerical simulations in this study were run on Stampede from the Extreme Science and Engineering Discovery Environment (XSEDE), which is supported by National Science Foundation grant number ACI-1053575. The Instituto Geofísico del Perú, Departamento de Geofísica, Universidad de Chile, Comité de la Base Nacional de Datos de Sismos Fuertes, Mexico, and the National Research Institute for Earth Science and Disaster Prevention (NIED), Japan provided ground motions used in this study.

\section{REFERENCES}

Abrahamson, N. A., and Silva, W. J. (1996). Empirical Ground Motion Models. Report to Brookhaven National Laboratory, Upton, NY.

Ancheta, T. D., Darragh, R. B., Stewart, J. P., Seyhan, E., Silva, W. J., Chiou, B. S. J., Wooddell, K. E., Graves, R. W., Kottke, A. R., Boore, D. M., Kishida, T., and Donahue, J. L. (2013). PEER NGA-West2 Database. PEER 2013/03. Pacific Earthquake Engineering Research Center, Berkeley, CA.

Arias, A. (1970). “A measure of earthquake intensity." Seismic Design for Nuclear Power Plants, R. J. Hansen, ed., The MIT Press, Cambridge, MA, 438-483.

ASCE. (2010). Minimum Design Loads for Buildings and Other Structures. ASCE/SEI 7-10. American Society of Civil Engineers, Reston, VA.

Baker, J. W., and Cornell, C. A. (2005). "A vector-valued ground motion intensity measure consisting of spectral acceleration and epsilon." Earthquake Engineering \& Structural Dynamics, 34(10), $1193-1217$. 
Baker, J. W., and Cornell, C. A. (2006). Vector-Valued Ground Motion Intensity Measures for Probabilistic Seismic Demand Analysis. PEER 2006/08. Pacific Earthquake Engineering Research Center, Berkeley, CA.

Baker, J. W., Lin, T., Shahi, S. K., and Jayaram, N. (2011). New Ground Motion Selection Procedures and Selected Motions for the PEER Transportation Research Program. PEER 2011/03. Pacific Earthquake Engineering Research Center, Berkeley, CA.

Benjamin, J. R. (1988). A Criterion for Determining Exceedance of the Operating Basis Earthquake. EPRI Report NP-5930. Electric Power Research Institute, Palo Alto, CA.

Bolt, B. A. (1973). "Duration of strong ground motion." 5th World Conference on Earthquake Engineering, Rome, Italy, 1304-1313.

Bommer, J. J., Magenes, G., Hancock, J., and Penazzo, P. (2004). "The Influence of Strong-Motion Duration on the Seismic Response of Masonry Structures.” Bulletin of Earthquake Engineering, 2(1), 1-26.

Bommer, J. J., and Martinez-Pereira, A. (1999). "The Effective Duration of Earthquake Strong Motion." Journal of Earthquake Engineering, Taylor \& Francis, 3(2), 127-172.

Bommer, J. J., Stafford, P. J., and Alarcón, J. E. (2009). "Empirical Equations for the Prediction of the Significant, Bracketed, and Uniform Duration of Earthquake Ground Motion." Bulletin of the Seismological Society of America, 99(6), 3217-3233.

Boore, D. M. (2005). “On Pads and Filters: Processing Strong-Motion Data." Bulletin of the Seismological Society of America, Seismological Society of America, 95(2), 745-750.

Boore, D. M., and Bommer, J. J. (2005). "Processing of strong-motion accelerograms: needs, options and consequences." Soil Dynamics and Earthquake Engineering, 25(2), 93-115.

Bradley, B. A. (2010). "A generalized conditional intensity measure approach and holistic groundmotion selection.” Earthquake Engineering \& Structural Dynamics, 39(12), 1321-1342.

Bradley, B. A. (2011). "Correlation of Significant Duration with Amplitude and Cumulative Intensity Measures and Its Use in Ground Motion Selection." Journal of Earthquake Engineering, 15(6), 809-832.

Chai, Y. H., and Fajfar, P. (2000). "A Procedure for Estimating Input Energy Spectra for Seismic Design.” Journal of Earthquake Engineering, Taylor \& Francis, 4(4), 539-561.

Cornell, C. A. (1997). “Does Duration Really Matter?” FHWA/NCEER Workshop on the National Representation of Seismic Ground Motion for New and Existing Highway Facilities, National Center for Earthquake Engineering Research, Burlingame, CA, 125-133.

Cosenza, E., and Manfredi, G. (1997). "The improvement of the seismic-resistant design for existing and new structures using damage criteria." Seismic Design Methodologies for the Next Generation of Codes, H. Krawinkler and P. Fajfar, eds., Balkema, Rotterdam, 119-130.

Deierlein, G. G., Reinhorn, A. M., and Willford, M. R. (2010). Nonlinear structural analysis for seismic design. NEHRP Seismic Design Technical Brief No. 4. National Institute of Standards and Technology, Gaithersburg, MD.

FEMA. (2009). Quantification of Building Seismic Performance Factors. FEMA P695. Federal Emergency Management Agency, Washington, D.C.

FEMA. (2012). Seismic Performance Assessment of Buildings, Volume 1 - Methodology. FEMA P58-1. Federal Emergency Management Agency, Washington, D.C.

FEMA. (2014). (in press). Appendix A of Seismic Performance Assessment of Buildings, Volume 5 Use of Seismic Performance Assessment Methodologies to Evaluate Code Performance. FEMA P-58-5. Federal Emergency Management Agency, Washington, D.C.

Foschaar, J. C., Baker, J. W., and Deierlein, G. G. (2011). "Preliminary Assessment of Ground Motion Duration Effects on Structural Collapse." 15th World Conference on Earthquake Engineering, Lisbon, Portugal. 
Gupta, A., and Krawinkler, H. (2000). "Dynamic P-Delta Effects for Flexible Inelastic Steel Structures.” Journal of Structural Engineering, 126(1), 145-154.

Hancock, J., and Bommer, J. J. (2006). "A State-of-Knowledge Review of the Influence of StrongMotion Duration on Structural Damage.” Earthquake Spectra, 22(3), 827-845.

Hancock, J., and Bommer, J. J. (2007). "Using spectral matched records to explore the influence of strong-motion duration on inelastic structural response." Soil Dynamics and Earthquake Engineering, 27(4), 291-299.

Haselton, C. B., Baker, J. W., Liel, A. B., and Deierlein, G. G. (2011). "Accounting for GroundMotion Spectral Shape Characteristics in Structural Collapse Assessment through an Adjustment for Epsilon." Journal of Structural Engineering, American Society of Civil Engineers, 137(3), 332-344.

Haselton, C. B., and Deierlein, G. G. (2007). Assessing seismic collapse safety of modern reinforced concrete moment frame buildings. PEER 2007/08. Pacific Earthquake Engineering Research Center, Berkeley, CA.

Haselton, C. B., Liel, A. B., Lange, S. T., and Deierlein, G. G. (2008). Beam-column element model calibrated for predicting flexural response leading to global collapse of $R C$ frame buildings. PEER 2007/03. Pacific Earthquake Engineering Research Center, Berkeley, CA.

Ibarra, L. F., Medina, R. A., and Krawinkler, H. (2005). "Hysteretic models that incorporate strength and stiffness deterioration." Earthquake Engineering \& Structural Dynamics, 34(12), 14891511.

Iervolino, I., Manfredi, G., and Cosenza, E. (2006). "Ground motion duration effects on nonlinear seismic response." Earthquake Engineering \& Structural Dynamics, 35(1), 21-38.

Jalayer, F. (2003). "Direct probabilistic seismic analysis: Implementing non-linear dynamic assessments." Ph.D. Dissertation, Stanford University.

Kayen, R. E., and Mitchell, J. K. (1997). "Assessment of Liquefaction Potential during Earthquakes by Arias Intensity." Journal of Geotechnical and Geoenvironmental Engineering, American Society of Civil Engineers, 123(12), 1162-1174.

Kempton, J. J., and Stewart, J. P. (2006). "Prediction Equations for Significant Duration of Earthquake Ground Motions Considering Site and Near-Source Effects." Earthquake Spectra, 22(4), 985-1013.

Kramer, S. L., and Mitchell, R. A. (2006). "Ground Motion Intensity Measures for Liquefaction Hazard Evaluation.” Earthquake Spectra, 22(2), 413-438.

Krawinkler, H. (1997). "Impact of duration/energy in design." FHWA/NCEER Workshop on the National Representation of Seismic Ground Motion for New and Existing Highway Facilities, National Center for Earthquake Engineering Research, Burlingame, CA, 115-123.

Kunnath, S. K., and Chai, Y. H. (2004). "Cumulative damage-based inelastic cyclic demand spectrum.” Earthquake Engineering \& Structural Dynamics, 33(4), 499-520.

Kutner, M. H., Nachtsheim, C., and Neter, J. (2004). Applied Linear Regression Models. McGrawHill/Irwin.

Luco, N., and Cornell, C. A. (2007). "Structure-Specific Scalar Intensity Measures for Near-Source and Ordinary Earthquake Ground Motions." Earthquake Spectra, 23(2), 357-392.

Mahin, S. A. (1980). "Effects of duration and aftershocks on inelastic design earthquakes." 7th World Conference on Earthquake Engineering, Istanbul, Turkey, 677-680.

Malhotra, P. K. (2002). "Cyclic-demand spectrum." Earthquake Engineering \& Structural Dynamics, 31(7), 1441-1457.

McKenna, F., Fenves, G. L., and Scott, M. H. (2006). "OpenSees: Open system for earthquake engineering simulation." Pacific Earthquake Engineering Research Center, University of California, Berkeley, CA., http://opensees.berkeley.edu. 
Moehle, J., and Deierlein, G. G. (2004). "A Framework Methodology for Performance-Based Earthquake Engineering." 13th World Conference on Earthquake Engineering, Vancouver, Canada.

Montejo, L. A., and Kowalsky, M. J. (2008). "Estimation of Frequency-Dependent Strong Motion Duration Via Wavelets and Its Influence on Nonlinear Seismic Response." Computer-Aided Civil and Infrastructure Engineering, 23(4), 253-264.

Ou, Y.-C., Song, J., Wang, P.-H., Adidharma, L., Chang, K.-C., and Lee, G. C. (2014). "Ground Motion Duration Effects on Hysteretic Behavior of Reinforced Concrete Bridge Columns." Journal of Structural Engineering, American Society of Civil Engineers, 140(3).

Oyarzo-Vera, C., and Chouw, N. (2008). "Effect of earthquake duration and sequences of ground motions on structural responses." 10th International Symposium on Structural Engineering for Young Experts, Changsha, China.

PEER. (2010a). Guidelines for Performance-Based Seismic Design of Tall Buildings. PEER 2010/05. Pacific Earthquake Engineering Research Center, Berkeley, CA.

PEER. (2010b). "Concrete Column Blind Prediction Contest.” Pacific Earthquake Engineering Research Center, Berkeley, CA, <http://nisee2.berkeley.edu/peer/prediction_contest/>.

Raghunandan, M., and Liel, A. B. (2013). "Effect of ground motion duration on earthquake-induced structural collapse." Structural Safety, 41, 119-133.

Rahnama, M., and Manuel, L. (1996). "The effect of strong motion duration on seismic demands." 11th World Conference on Earthquake Engineering, Acapulco, Mexico.

Sarieddine, M., and Lin, L. (2013). "Investigation Correlations between Strong-motion Duration and Structural Damage." Structures Congress 2013, American Society of Civil Engineers, Reston, VA, 2926-2936.

Sideras, S. S., and Kramer, S. L. (2012). "Potential Implications of Long Duration Ground Motions on the Response of Liquefiable Soil Deposits." 9th International Conference on Urban Earthquake Engineering / 4th Asia Conference on Earthquake Engineering, Tokyo, Japan.

Sucuoglu, H., and Nurtug, A. (1995). "Earthquake ground motion characteristics and seismic energy dissipation.” Earthquake Engineering \& Structural Dynamics, 24(9), 1195-1213.

Tremblay, R. (1998). "Development of design spectra for long-duration ground motions from Cascadia subduction earthquakes." Canadian Journal of Civil Engineering, NRC Research Press Ottawa, Canada, 25(6), 1078-1090.

Trifunac, M. D., and Brady, A. G. (1975). "A study on the duration of strong earthquake ground motion." Bulletin of the Seismological Society of America, 65(3), 581-626.

Vamvatsikos, D., and Cornell, C. A. (2002). "Incremental dynamic analysis." Earthquake Engineering \& Structural Dynamics, 31(3), 491-514.

Xie, L.-L., and Zhang, X. (1988). "Engineering Duration of Strong Motion and its Effects on Seismic Damage." 9th World Conference on Earthquake Engineering, Tokyo, Japan, 307-312.

Zahrah, T. F., and Hall, W. J. (1984). "Earthquake Energy Absorption in SDOF Structures." Journal of Structural Engineering, American Society of Civil Engineers, 110(8), 1757-1772. 